\title{
ANÁLISE DA PESQUISA TRACKING DE SATISFAÇÃO DOS CLIENTES DA INGRESSO.COM NA EMPRESA CINEMẢTOGRÁFICA $\mathbf{X}$
}

Analysis of the ingresso.com client satisfaction tracking research in the cinematographic company $\mathrm{x}$

Análisis de la investigación de seguimiento de satisfacción del cliente ingresso.com en la empresa cinematográfica $\mathrm{x}$

Received: may/2020

Accepted: june/2020

Available online: june/2020

Alexandre Formigoni, Doutor em Engenharia de Produção, Unidade de Pós Graduação. Pesquisa e Extensão do Centro Paula Souza. Mestrado Profissional em Gestão de Sistemas Produtivos, Brasil. E-mail: a_formigoni@yahoo.com.br

Roberto Padilha Moia, Doutor em Administração de Empresas, Fatec Sebrae - CPS, Brasil. E-mail: robertopadilha@uol.com.br

Caio Flávio Stettiner, Mestre em Educação, Universidade/Instituição: Fatec Sebrae - CPS, Brasil, E-mail: cstettiner@gmail.com

José Abel de Andrade Baptista, Mestre em Administração de Empresas, Universidade/Instituição: Fatec Zona Leste - CPS, Brasil.

E-mail: abel_baptista@yahoo.com.br

Resumo: O objetivo principal deste artigo é analisar a pesquisa tracking (monitoramento) de satisfação dos clientes da ingresso.com da empresa cinematográfica X, localizada na zona leste da capital de São Paulo. Para alcançar este objetivo utilizamos um cálculo para mensurar a satisfação, chamado Net Promoter Score (NPS). Os materiais analisados foram coletados de fevereiro/19 até setembro/19, nos apresentando uma amostra de 163 clientes. Por meio dos dados coletados conclui-se que a satisfação dos clientes encontra-se de acordo com o estabelecido pela gestão da empresa. O número de promotores é alto, mostrando que a empresa possui, de certa maneira, um bom relacionamento com os clientes e está bem conceituada no mercado, no entanto, sugerimos que a atenção seja voltada também aos detratores, que apesar de baixo, pode apontar importantes ressalvas para melhorar os serviços da empresa podendo retornar e até trazer novos clientes em potencial. 
Palavras-chave : Pesquisa tracking, Satisfação do cliente, Net promoter score.

\begin{abstract}
The main purpose of this article is to analyze the tracking research (monitoring) of customer satisfaction of ingresso.com the film company X, located on the east side of the São Paulo capital. To achieve this goal we use a calculation to measure satisfaction, called the Net Promoter Score (NPS). The materials analyzed were collected from February / 19 to September / 19, in presenting a sample of 163 customers. Through the data collected it is concluded that customer satisfaction is in accordance with the established by the management of the company. The number of promoters is high, showing that the company has, in a certain way, a good relationship with customers and is well respected in the market. However, we suggest that attention should also be directed to detractors, which, although low, may point important caveats to improve the company's services can return and even bring new potential customers.
\end{abstract}

Keywords: Search tracking, Customer satisfaction, net promoter score.

Resumen: El objetivo principal de este artículo es analizar la encuesta de seguimiento de la satisfacción del cliente de ingresso.com de la compañía cinematográfica X, ubicada en el lado este de la capital de São Paulo. Para lograr este objetivo, usamos un cálculo para medir la satisfacción, llamado Net Promoter Score (NPS). Los materiales analizados fueron recolectados del 19 de febrero al 19 de septiembre, presentando una muestra de 163 clientes. A través de los datos recopilados, se puede concluir que la satisfacción del cliente está de acuerdo con lo establecido por la administración de la empresa. El número de promotores es alto, lo que demuestra que la compañía tiene, en cierta forma, una buena relación con los clientes y está bien considerada en el mercado, sin embargo, sugerimos que la atención también se dirija a los detractores, quienes, a pesar de ser bajos, pueden señalar advertencias importantes para mejorar los servicios de la compañía y poder regresar e incluso atraer nuevos clientes potenciales.

Palabras clave: Investigación de seguimiento, satisfacción del cliente, puntaje neto del promotor.

\title{
INTRODUÇÃO
}

Com o advento da internet, compras online tornou-se algo comum no dia a dia de muitas pessoas do mundo. Todos os tipos de itens são vendidos on-line, de produtos a serviços em geral, e isto não seria diferente tratando-se da venda de ingressos para o cinema.

Em 2018 o público que esteve nos cinemas, segundo a Agência Nacional do Cinema (ANCINE), foi de aproximadamente 160 milhões sendo que a maior bilheteria do mesmo ano pertenceu ao filme Vingadores: Guerra Infinita. Diante deste cenário, os estabelecimentos de cinemas precisam focar em atender bem não apenas o público que compram seus ingressos na bilheteria, mas também o público que procura a facilidade das vendas online, e atendê-los também com destreza para que ambos saiam satisfeitos, uma vez que possuem diversas redes de cinemas no mercado para escolher, mas, um cliente satisfeito pode se tornar um cliente fiel. 
Segundo Portaluppi et al. (2006, p.81) "Clientes fiéis representam um volume substancial dos lucros de uma organização, e esta não deve arriscar a perder um cliente, pois perder clientes lucrativos pode afetar drasticamente os lucros de uma empresa". Portanto conhecer o tamanho da sua marca no mercado e entender o seu público é imprescindível para manter um relacionamento com o cliente e um dos meios para atingir tal missão é através da pesquisa tracking (ou monitoramento) que ajudará a empresa a monitorar o nível da satisfação do cliente ao longo do tempo para que possa tomar decisões ágeis diante de cada cenário.

O presente artigo tem o objetivo de apresentar uma análise da experiência do cliente identificada através de uma pesquisa tracking (monitoramento) de satisfação na empresa cinematográfica X, localizada na Zona Leste de São Paulo. O foco desta análise é em clientes que adquiriram seus ingressos através da plataforma da Ingresso.com, um site/aplicativo de vendas de ingresso de diferentes redes de cinemas com mais de 10 milhões de usuários inscritos, que procuram utilizar este meio para diminuir o tempo em filas nos estabelecimentos cinematográficos.

Para a análise foi utilizado o cálculo NPS (Net Promoter Score), uma métrica, criada em 2003, por Fred Reichheld que tem como objetivo mensurar a satisfação e o relacionamento entre clientes e empresas, e nos possibilitou medir o grau de satisfação dos clientes do cinema, verificando a quantidade de promotores, neutros e detratores.

Na primeira parte, foi explicado o que é e-commerce, com os mais recentes dados, explicamos a importância de satisfazer seus clientes e quais ferramentas existem para medir o quão satisfeitos o consumidor se encontra com seu produto/serviço. Após definirmos o que é e como usar o cálculo NPS, apresentamos os dados coletados da pesquisa de satisfação da empresa cinematográfica $\mathrm{X}$, como quantidade de clientes entrevistados, promotores, neutros, detratores por mês e um cálculo acumulado.

RBPPD/BRJPD | Vol. 2 | n. 2 | p. 72-86, 2020. 


\section{FUNDAMENTAÇÃO TEÓRICA}

\section{E-commerce}

O comércio eletrônico é nossa realidade atualmente, compras de produtos e serviços são feitas diariamente ao redor do mundo. A maior premissa do e-commerce, termo comum utilizado para esse meio de transação, é facilitar "o processo de compra do consumidor ressaltando a comodidade de efetuar as compras em casa ou no trabalho" (BARROS; MUYLDER; OLIVEIRA, 2007, p.2).

Com o avanço da tecnologia e a facilidade da transação do comércio eletrônico, tornase muito mais fácil o crescimento deste meio. Portanto define-se comércio eletrônico como:

A realização de comunicações e transações de negócios através de redes de computadores, mais especificamente a compra e venda de produtos e serviços, e a transferência de fundos por meio de comunicações digitais" (REEDY; SCHULLO; ZIMMERMAN, 2001, p.26).

Este mercado é amplo e abrangente e pode ser aplicado em diversos processos de negócios, afim de criar várias demandas ou de tornar mais eficiente a maiorias dos processos. Estes processos estão divididos em: empresa-a-empresa (B2B), empresa-a-consumidores (B2C), Consumidor -a- empresa (C2B), Consumidor-a-consumidor (C2C), Comércio intraorganizacional (intrabusiness), Governo para cidadãos (G2C) e outros, Comércio cooperativo (c-commerce), Comércio móvel (m-commerce). O mais conhecido e adotado é B2C, estilo de comércio eletrônico varejista em forma de catálogo no qual o consumidor tem a possibilidade de realizar a compra. (TURBAN, MCLEAN; WETHERBE, 2004).

O mercado Brasileiro, na área de comércio eletrônico, aponta um crescente aumento no faturamento a cada ano. De acordo com Wolf (2019), o faturamento do comércio eletrônico no Brasil foi de 53,2 bi de reais em 2018, um aumento de 11\% se comparado com 2017 e ainda 
projetou um aumento de $15 \%$ do faturamento para 2019. O mercado digital inclui consumidores de todas as classes (A, B, C e D) que em 2017, apenas no Brasil, foi mais de 50 milhões de compradores online e a tendência é só crescer.

Com estes dados é perceptível o crescimento dos e-commerce no Brasil e da mesma maneira, a necessidade de satisfazer os consumidores que frequentam a sua loja ou consomem seus produtos pessoalmente, é necessário redobrar a atenção quando se trata de e-consumidores que podem se tornar leais ao seu comércio, ou seja, clientes, para tal é necessário criar estratégias e ferramentas específicas para ganhar a confiança, satisfação e consequentemente fidelização dos clientes.

Segundo Kotler (2000), um cliente satisfeito é a essência da empresa, custa menos, permanece fiel por mais tempo, compra mais à medida que novos produtos são lançados, fala bem da organização e é menos propenso a olhar para outras marcas.

\section{Satisfação do consumidor}

A importância da Satisfação do Consumidor é um dos principais objetivos das organizações (HEPP, 2008).

Se as empresas optassem por não fazer essa pesquisa sobre a satisfação de seus clientes, não saberiam o que precisaria ser melhorado e consequentemente sua empresa demonstraria um lucro muito baixo, podendo vir a falência. Muitos clientes retornam periodicamente a uma empresa por causa da maneira como são tratados pelos funcionários (BARNES, 2002).

A eficácia do treinamento desses funcionários é observado no atendimento ao cliente, se foram gentis ou se há displicência, caso ocorra a segunda opção, logo fica evidenciado a má escolha na contratação. A satisfação do cliente, seja ele no mercado que for, é responsável pela existência da empresa (HOFFMAN, 2010).

Fornell et al (1996) propuseram um modelo que avalia o índice de satisfação pela percepção do cliente. Através de um construto chamado American Customer Satisfaction Index 
(ACSI), os autores demonstram que a satisfação total do cliente está ligada aos princípios do seu envolvimento com a empresa (expectativa, qualidade e valor percebido) e que resultam em dois pressupostos: a fidelização ou a reclamação.

\section{Ferramentas para acompanhar e medir a satisfação do cliente}

Segundo Walker (1991), o melhor marketing é feito por meio dos próprios clientes. Os clientes fazem comentários de suas boas e más experiências e hoje, com a internet, estes comentários não são apenas pelo boca-a-boca. Existem sites de relacionamento e até plataformas próprias direcionadas aos feedbacks bons ou ruins. Um exemplo deste seria o Reclame Aqui, site ideal para concentrar reclamações de todos os tipos de empresas.

Com isso acompanhar e medir a satisfação dos clientes se faz necessário para conhecer o nicho do qual sua empresa está atraindo, o quão satisfeitos os clientes estão com a experiência de consumir em sua empresa e com isso criar estratégias para conquistar clientes fiéis.

Quadro 1: Fonte de ideias para medir e melhorar o atendimento

Pesquisas de Satisfação de Clientes: menos de 5\% dos clientes insatisfeitos reclamam, estes preferem comprar de outro fornecedor. Empresas proativas medem a satisfação de clientes diretamente, realizando pesquisas periódicas. Um alto índice positivo de propaganda "boca a boca" indica que a empresa está produzindo alto nível de satisfação de clientes;

Compras Simuladas: empresas contratam pessoas para se passar por compradores potenciais, com objetivo de relatar pontos fortes e fracos, esses compradores, podem testar se a equipe de vendas está preparada para lidar com diversas situações;

Análise de Clientes Perdidos: as empresas devem contatar os clientes que deixaram de comprar, a fim de verificar porque isso aconteceu. Se os índices de perda estiverem crescendo, existe um indício de que a empresa não está conseguindo deixar seus clientes satisfeitos.

Sistemas de Reclamações e Sugestões: uma organização centrada no cliente facilita o recebimento de sugestões e reclamações. As empresas estão aderindo a páginas da web e e-mail para facilitar a comunicação, esses fluxos de informações oferecem muitas boas idéias às empresas e permitem que elas ajam com rapidez para solucionar problemas;

Fonte: PORTALUPPI et al (2006)

Pesquisa de Satisfação do Consumidor

RBPPD/BRJPD | Vol. 2 | n. 2 | p. 72-86, 2020. 
A pesquisa de satisfação é a forma na qual a empresa fica ciente se seu produto ou serviço está sendo entregue ao cliente, se deu algum problema com a comida adquirida, na limpeza do ambiente ou mesmo na projeção do filme. Se o desempenho não alcançar as expectativas, o cliente ficará insatisfeito. Se o desempenho alcançar as expectativas, o cliente ficará satisfeito. Se o desempenho for além das expectativas, o cliente ficará altamente satisfeito ou encantado (KOTLER, 2000).

Segundo pesquisas realizadas por Hoffman (2010), pode haver uma quebra de expectativa do cliente ao adquirir o serviço e perceber que não era da forma como imaginava. Se a experiência não for das melhores, o consumidor desse serviço pode optar pelo do concorrente, que aos olhos dele, é mais agradável e supera suas expectativas.

De acordo com Blackwell, Miniard e Engel (2011), a razão para que as empresas se preocupam com a satisfação de seus consumidores, está ligada com a decisão de seus clientes em adquirir seus produtos ou serviços. Essas avaliações pós-compra mostram o que está bom e o que precisa ser melhorado para satisfação e fidelização do cliente, pois os que não tiveram suas expectativas alcançadas, não irão retornar na empresa.

\section{MATERIAIS E MÉTODOS}

Para a realização desta análise foi utilizada a pesquisa tracking de satisfação da empresa cinematográfica X (zona leste/SP), aplicados a partir de fevereiro/2019. Esta empresa encontrase no mesmo local há cerca de 4 anos e possui grande público, sendo registrado em abril mais de 7 mil pessoas na semana de lançamento do filme Vingadores.

A pesquisa tracking (ou monitoramento) de satisfação identifica as oscilações no nível de satisfação ao longo do tempo. Assim, os gestores podem tomar atitudes de forma ágil, evitando prejuízo para a empresa. Estas pesquisas foram aplicadas diariamente na empresa, de segunda a segunda, apenas com clientes que compraram seus ingressos através da plataforma 
da Ingresso.com, a fim de identificar o comportamento e preferências destes clientes e se eles se encontram satisfeitos com suas experiências no cinema.

Compilamos o resultado da pesquisa através do cálculo NPS (Net Promoter Score), uma ferramenta que busca medir as reais necessidades dos clientes e, para Oliveira, Sanguineto e Santos (2015), apesar de ser uma ferramenta simples, através dos depoimentos coletados dos clientes é possível registrar os principais pontos que os clientes observam nos produtos/serviços e atendimentos da empresa e, partir disso, fazer melhorias. O método de cálculo NPS tem o objetivo de categorizar os clientes em grupos, para isso é necessário realizar perguntas chaves que possam ser respondidas em uma escala de 0 a 10. Estes grupos são três, conforme descrito abaixo:

Promotores: pessoas com notas de 9 a 10, indicando que sua vida melhorou depois do relacionamento com a empresa, geralmente compram mais de uma vez e recomendam a amigos ou colegas, são leais a empresa e oferecem feedback construtivo e sugestões.

Neutros: pessoas com notas 7 a 8 , compram o que precisam e nada mais, são clientes passivamente satisfeitos, não leais, quase não fazem recomendações e quando fazem é com ressalvas e sem entusiasmo. Não podem ser contabilizados como ativo de longo prazo. A meta das empresas para os clientes neutros é melhorar seus serviços/produtos e processos para tentar transformá-los em promotores.

Detratores: pessoas que dão nota inferior ou igual a 6 , indicando que sua vida piorou depois do relacionamento com a empresa. É um grupo de indivíduos insatisfeitos, decepcionados, que se sentem consternados pelo tratamento recebido e criticam a empresa a amigos e colegas (REICHHELD, 2011).

RESULTADOS E DISCUSSÃO

RBPPD/BRJPD | Vol. 2 | n. 2 | p. 72-86, 2020. 
Desde fevereiro de 2019, a empresa cinematográfica X aplicou um questionário com 14 perguntas para conhecer a experiência que o cliente teve durante sua permanência no estabelecimento envolvendo bomboniere/snack bar, lobby, banheiro e sala, incluindo qualidade do lugar, do atendimento e dos alimentos (se adquirido). O cliente, pode responder sobre sua experiência a nivelando em uma escala de 0 a 10, podendo fazer alguns comentários adicionais, se desejar, e por fim, ele dá uma nota de 0 a 10 para a satisfação geral do serviço.

De fevereiro até setembro foram entrevistados 163 clientes que adquiriram seus ingressos na Ingresso.com, a distribuição ocorreu conforme tabela abaixo, sendo, em média 20,4 clientes por mês.

Tabela 2: Total de clientes

\begin{tabular}{|l|l|l|l|l|l|l|l|l|}
\hline Mês & Fev & Mar & Abr & Mai & Jun & $\begin{array}{l}\text { Ju } \\
\text { I }\end{array}$ & $\begin{array}{l}\text { Ag } \\
\text { o }\end{array}$ & Set \\
\hline $\begin{array}{l}\text { Cliente } \\
\text { s }\end{array}$ & 19 & 6 & 16 & 10 & 38 & 43 & 11 & 20 \\
\hline
\end{tabular}

Fonte: elaborado pelos autores (2019)

De acordo com as notas dadas os clientes foram classificados como detratores, neutros e promotores, sendo que $100 \%$ dos detratores foram identificados em junho, que coincide com as férias escolares, mês do qual o estabelecimento normalmente tem uma superlotação por se tratar de um meio de entretenimento. Ainda que o método NPS seja realizado diariamente, bons resultados não podem ser idealizados imediatamente. A melhoria é de longo prazo sendo, portanto, necessário que a empresa envolva todos os colaboradores na missão de tornar os detratores em promotores.

Tabela 3: Promotores, Neutros e Detratores por mês

\begin{tabular}{|l|l|l|l|l|l|l|l|l|}
\hline Meses & FEV & MAR & $\begin{array}{l}\text { AB } \\
\text { R }\end{array}$ & $\begin{array}{l}\text { MA } \\
\text { I }\end{array}$ & JUN & JUL & AGO & SET \\
\hline $\begin{array}{l}\text { Detratore } \\
\text { s }\end{array}$ & 0 & 0 & 0 & 0 & 2 & 0 & 0 & 0 \\
\hline Neutros & 2 & 0 & 2 & 2 & 12 & 11 & 3 & 5 \\
\hline $\begin{array}{l}\text { Promotor } \\
\text { es }\end{array}$ & 17 & 6 & 14 & 8 & 24 & 32 & 8 & 15 \\
\hline
\end{tabular}

RBPPD/BRJPD | Vol. 2 | n. 2 | p. 72-86, 2020. 
Fonte: autores (2019)

No gráfico 1, é possível analisar como o número de promotores, neutros e detratores sofreram alteração ao longo dos meses. É importante ressaltar que apesar do número de 163 clientes, houve muito mais transações de clientes da ingressso.com, contudo, não foi possível entrevistar a todos, devido ao baixo número de colaboradores responsáveis pela pesquisa (dois) e da dificuldade de entrevistar os clientes pois alguns que se recusaram em realizar a pesquisa, diminuindo assim o número de amostra.

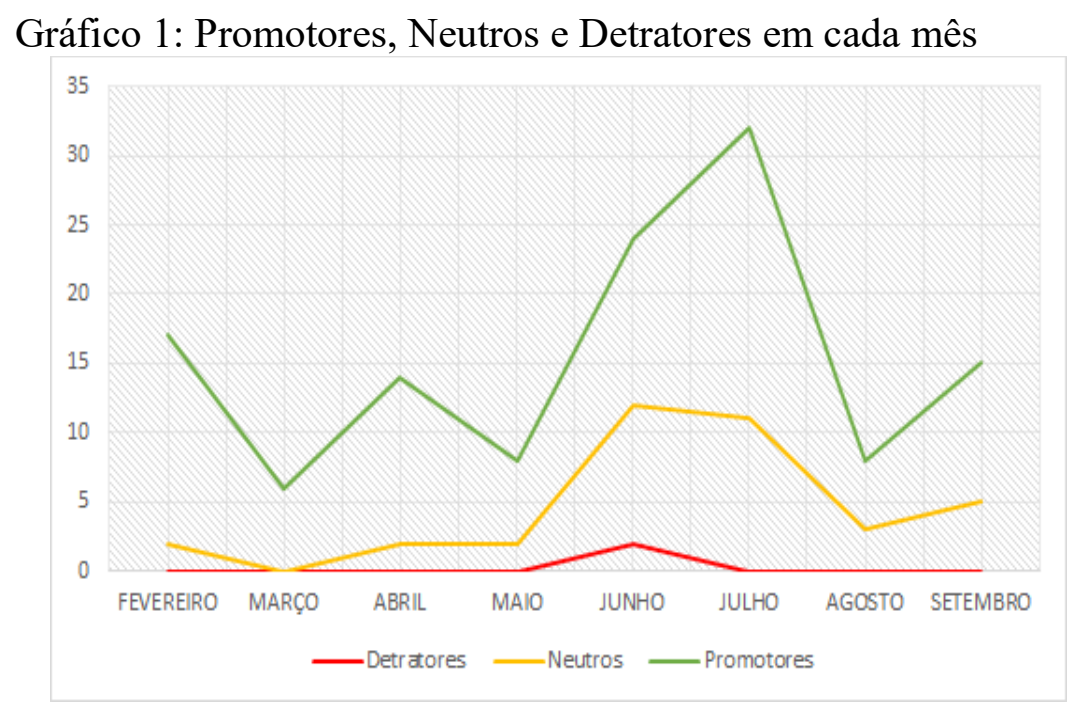

Fonte: autores (2019)

$\mathrm{Na}$ tabela 4, compilamos os resultados dos últimos 8 meses identificando que dos 163 clientes entrevistados houve 124 clientes classificados como promotores, 37 clientes como neutros e 2 clientes como detratores.

Tabela 4: Detratores, Neutros e Promotores em geral

\begin{tabular}{|l|l|l|}
\hline $\begin{array}{l}\text { Detrator } \\
\text { es }\end{array}$ & Neutros & $\begin{array}{l}\text { Promotor } \\
\text { es }\end{array}$ \\
\hline 2 & 37 & 124 \\
\hline
\end{tabular}

Fonte: autores (2019) 
Ao iniciar a pesquisa de satisfação, foi estabelecido que a meta do indicador entre as unidades do cinema da mesma rede seria de $75 \%$ por mês, com o objetivo principal de resolver imediatamente qualquer problema apresentado a clientes reclamantes, para que o mesmo pudesse sair do estabelecimento o mais satisfeito possível, aumentando as chances dele retornar e de indicar a empresa para outros. Na tabela 6, identificamos a percentagem de promotores, neutros e detratores.

Tabela 6: Porcentagem de Promotores, Neutros e Detratores por mês

\begin{tabular}{|l|l|l|l|l|l|l|l|l|}
\hline Meses & $\begin{array}{l}\text { FE } \\
\text { V }\end{array}$ & $\begin{array}{l}\text { MA } \\
\text { R }\end{array}$ & ABR & MAI & JUN & JUL & AGO & SET \\
\hline Detratores & $0 \%$ & $0 \%$ & $0 \%$ & $0 \%$ & $5 \%$ & $0 \%$ & $0 \%$ & $0 \%$ \\
\hline Neutros & $11 \%$ & $0 \%$ & $12 \%$ & $20 \%$ & $32 \%$ & $26 \%$ & $27 \%$ & $25 \%$ \\
\hline $\begin{array}{l}\text { Promotore } \\
\text { s }\end{array}$ & $89 \%$ & $\begin{array}{l}100 \\
\%\end{array}$ & $88 \%$ & $80 \%$ & $63 \%$ & $74 \%$ & $73 \%$ & $75 \%$ \\
\hline
\end{tabular}

Fonte: autores (2019)

Portanto em 8 meses, foram classificados $76 \%$ de promotores, $23 \%$ neutros e $1 \%$ de detratores, conforme gráfico 2.

Gráfico 2: Porcentagem dos detratores, neutros e promotores

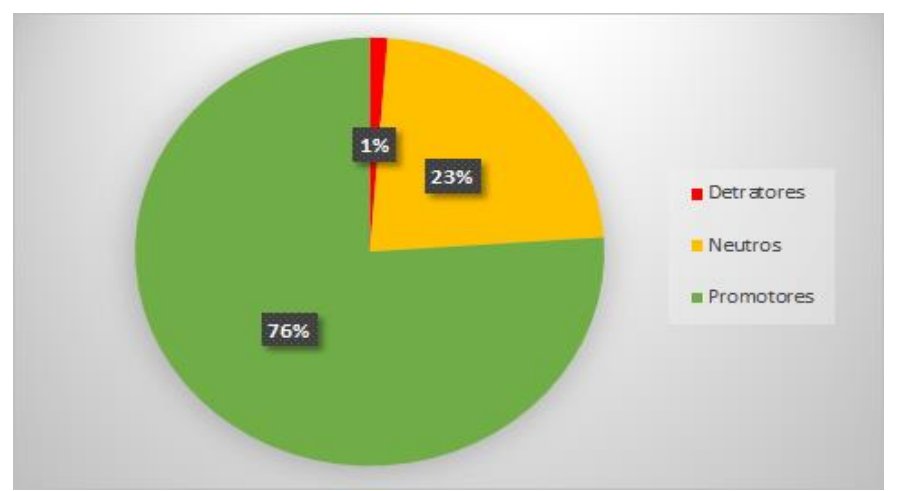

Fonte: autores (2019)

O NPS é aplicado subtraindo o percentual de clientes promotores (P) pelo percentual de clientes detratores (D), e o resultado percentual líquido é o de promotores, que seria o NPS, conforme figura 1 a seguir.

Figura 1 : Cálculo de Tracking Satisfação 


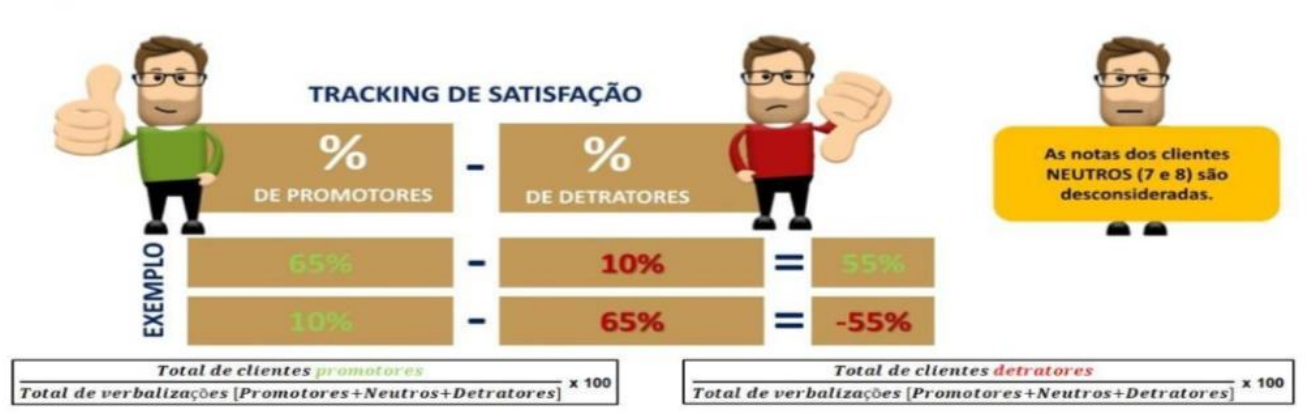

Fonte: relatório da empresa cinematográfica X (2019)

Os neutros não são contabilizados pois trata-se de clientes que não estão totalmente satisfeitos, ou seja, podem até recomendar a empresa, mas a faz com ressalvas, sendo assim, não são considerados clientes leais.

Para Cunha (2018) é comum que clientes neutros deixem em média 10\% a menos de comentários em relação aos detratores, que habitualmente, devido à má experiência possuem mais comentários. Conforme descreve: Pelo fato de terem uma experiência indiferente, acabam não tendo engajamento até mesmo na hora de deixar um comentário sobre a experiência que obteve com a empresa (CUNHA, 2018).

Seguindo o cálculo, a empresa de cinemas possui $75 \%$ de promotores (NPS=76\% - 1\% $=75 \%$ ) no total, no entanto o mês de junho foi o mês com o menor número de promotores chegando a $58 \%(\mathrm{NPS}=63 \%-5 \%=58 \%)$.

\section{Conclus Ão}

Nosso principal objetivo foi analisar as pesquisas de monitoramento de satisfação dos clientes de uma empresa cinematográfica, verificando e mensurando o nível de satisfação, através do método NPS, classificando os clientes em promotores, neutros e detratores.

A pesquisa vem sendo aplicada há 8 meses com questionamentos sobre a experiência do cliente no cinema. Quando a nota do cliente é abaixo do esperado, a empresa busca minimizar a insatisfação oferecendo ingressos para uma nova experiência ou outro combo, se 
a reclamação for relacionada ao alimento adquirido. Contudo, além dessas ações, sugerimos que a atenção seja voltada aos detratores objetivando que nas próximas visitas virem neutros, e os neutros virem promotores, assim aumentando o índice do tracking, indicador da empresa para clientes da Ingresso.com.

Sendo assim, para os neutros e detratores, sugerimos seja acrescentada na pesquisa da empresa a pergunta: “O que poderia ser melhorado numa próxima experiência? ”, para que assim a empresa possa analisar e melhorar o ponto negativo mencionado, buscando melhorar o serviço não só para o cliente que apontou aquele problema, mas também atrair novos clientes.

A pesquisa NPS vem sendo amplamente analisada pelos gestores sendo o maior foco da empresa a qualidade, seja no atendimento, limpeza ou qualidade dos alimentos. Há investimento pesado na manutenção de treinamento dos atendentes e vistorias frequentes de empresas terceirizadas de segurança alimentar e de higiene.

Entretanto a maior desvantagem para a empresa ocorre em momentos que saem da alçada do estabelecimento, momentos estes que arruínam a estadia do cliente e, consequentemente, pode alterar sua nota na pesquisa, como por exemplo, uma queda de luz no bairro.

Contudo, trata-se de um método válido uma vez que através da qualidade em seus setores, diferencial que a empresa busca como missão, a pesquisa tracking (monitoramento) vem auxiliando no crescimento do relacionamento da empresa com o cliente, trazendo credibilidade e confiança, além de apontar possíveis falhas que podem estar afastando clientes em potencial, falhas essas que a empresa planeja identificar e corrigir.

\section{REFERÊNCIAS}

ANCINE. Parque exibidor brasileiro fecha o ano de 2018 com maior número de salas

desde os anos 1970. Disponível em: https://www.ancine.gov.br/pt-br/sala-

RBPPD/BRJPD | Vol. 2 | n. 2 | p. 72-86, 2020. 
imprensa/noticias/parque-exibidor-brasileiro-fecha-o-ano-de-2018-com-maior-n-mero-desalas. Acesso em: 03 setembro 2019.

BARNES, J. Segredos da Gestão pelo Relacionamento com os clientes: É tudo uma questão de como você faz com que eles se sintam. Rio de Janeiro: Qualitymark, 2002. BARROS, L.; MUYLDER, C.; OLIVEIRA, M. S. C. Tendência de Compras pela Internet versus Compras Tradicionais: Um Estudo Exploratório. 1 Encontro de Administração da Informática ENADI. Out, 2007.

BLACKWELL, R. D.; MINIARD, P. W.; ENGEL, J. F. Comportamento do consumidor. São Paulo: Cengage Learning, 2011.

CUNHA, P. Clientes Neutros: como eles impactam sua nota no NPS? 2018. Disponível em: https://satisfacaodeclientes.com/clientes-neutros-como-impactam-o-nps/ Acessado: $25 / 10 / 2019$.

FORNELL, C. et al. The American Customer Satisfaction Index: Nature, Purpose, and Findings. Journal of Marketing, v. 60, p. 7-18, 1996.

HEPP, T. C. P. Satisfação, lealdade e envolvimento do consumidor: um estudo no varejo de vestuário. In: 32o ENCONTRO NACIONAL DA ANPAD - ENANPAD, 2008. Anais... Rio de Janeiro: ANPAD, 2008.

HOFFMAN, K. D. Princípios de marketing de serviços: conceitos, estratégias, casos. 3. ed. São Paulo: Cengage Learning, 2010.

KOTLER, P. Análise dos mercados consumidores e do comportamento de compra. 10. ed. São Paulo: Pearson Prentice Hall, 2000.

OLIVEIRA, E; SANGUINETO, A; SANTOS, J. O Net Promoter Score (NPS) como forma de mensurar a satisfação dos clientes: O Caso Viana \& Moura Construções. Rev. Interfaces de Saberes, v.1, n.14, 2015.

PORTALUPPI, J.; HEINZMANN, L. M.; TAGLIAPIETRA, O. M.; BORILLI, S. P. Análise do atendimento e satisfação dos clientes: Estudo de caso de uma empresa de insumos agrículos. Rev. Ciên. Empresariais da UNIPAR, Umuarama, v.7, n.1, jan./jun, 2006. REEDY, J.; SCHULLO, S.; ZIMMERMAN, K. Marketing Eletrônico: a integração de recursos eletrônicos ao processo de marketing. Porto Alegre: Bookman, 2001.

RBPPD/BRJPD | Vol. 2 | n. 2 | p. 72-86, 2020. 
REICHHELD, F. A pergunta definitiva 2.0: Como as empresas que implementam o net promoter score prosperam em um mundo voltado aos clientes. Rio de Janeiro: Elsevier, 2011. TURBAN, E.; MCLEAN, E.; WETHERBE, J. Tecnologia Da Informação Para Gestão: Transformando os Negócios na Economia Digital. 3. ed. Porto Alegre, Bookman, 2004. WALKER, D. O cliente em primeiro lugar: o atendimento e a satisfação do cliente como uma arma poderosa de fidelidade e vendas. São Paulo: Makron Books, 1991 WOLF, G; Receita do e-commerce no Brasil foi de R\$ 53,2 bi em 2018, diz estudo. Disponível em: https://link.estadao.com.br/noticias/empresas,receita-do-e-commerce-nobrasil-foi-de-r-53-2-bi-em-2018-diz-ebit,70002767663 Acesso em: 31 outubro 2019. 